\title{
Statins modulate the expression profile of ATP-binding cassette transporters in human neuroblastoma cells
}

\author{
Bihter Atil, Evelyn Sieczkowski, Martin Hohenegger ${ }^{*}$ \\ From 17th Scientific Symposium of the Austrian Pharmacological Society (APHAR). Joint meeting with the \\ Hungarian Society of Experimental and Clinical Pharmacology (MFT) \\ Innsbruck, Austria. 29-30 September 2011
}

\section{Background}

The development of chemoresistance still is a major problem in cancer therapy. Mainly, impact of chemotherapy is based on the upregulation of ATP-binding cassette $(\mathrm{ABC})$ transporters, which correlates with bad prognosis and less chemotherapeutic success. Previously, we could show that the HMG-CoA reductase inhibitor simvastatin is able to inhibit the most prominent $A B C$ transporter ABCB1. Additionally, we demonstrated that simvastatin coadministrated with the anthracycline doxorubicin led to increased apoptosis in neuroblastoma cells, and that these effects were comparable with the potential of verapamil, a first generation inhibitor of ABCB1 [1].

\section{Methods}

The neuroblastoma cell line SH-SY5Y was used for our analyses. Alterations in the protein level of $A B C$ transporters were demonstrated by Western blot analyses and in more detail with FACS. RNA from SH-SY5Y cells treated with simvastatin for 6 and 72 hours was isolated, and the mRNA levels of various $A B C$ transporters were quantified by real-time PCR.

\section{Results}

Simvastatin exposure led to a concentration-dependent decrease of ABCB1. Similarly, FACS analyses demonstrated a significant decrease of ABCB1 expression on the cell surface. Moreover, doxorubicin-induced elevations in $\mathrm{ABCB} 1$ cell surface expression were reversed by

\footnotetext{
* Correspondence: martin.hohenegger@meduniwien.ac.at Institute of Pharmacology, Center of Physiology and Pharmacology, Medical University of Vienna, 1090 Vienna, Austria
}

simvastatin. However, compensation of $\mathrm{ABCB} 1$ by other $A B C$ transporters like $A B C C 1$ and $A B C C 4$ could not be detected. Conversely, ABCG2 showed upregulation on protein and mRNA level.

\section{Conclusions}

Here we show that simvastatin is able to modulate ABCB1 expression. This potential seems to be divided in immediate and long-term effects. Expression of ABCB1 was downregulated on protein as well as on mRNA level after long-term incubation and partially compensated by other $\mathrm{ABC}$ transporters. Moreover, we also observed short-term regulation of the cell surface expression without any changes in total cellular level which might be based on impact of simvastatin in ABCB1 turn-over. Based on our findings, we suggest that simvastatin is a promising candidate as an adjuvant chemotherapeutic drug to impair transporter-mediated multidrug resistance.

\section{Acknowledgements}

This work was funded by the Herzfeldersche Familienstiftung and FWF (P-22385).

Published: 5 September 2011

\section{Reference}

1. Sieczkowski E, Lehner C, Ambros PF, Hohenegger M: Double impact on p-glycoprotein by statins enhances doxorubicin cytotoxicity in human neuroblastoma cells. Int J Cancer 2010, 126:2025-2035.

\section{doi:10.1186/1471-2210-11-S2-A23}

Cite this article as: Atil et al:: Statins modulate the expression profile of ATP-binding cassette transporters in human neuroblastoma cells. BMC Pharmacology 2011 11(Suppl 2):A23.

\section{() Biomed Central}

(c) 2011 Atil et al; licensee BioMed Central Ltd. This is an open access article distributed under the terms of the Creative Commons Attribution License (http://creativecommons.org/licenses/by/2.0), which permits unrestricted use, distribution, and reproduction in any medium, provided the original work is properly cited. 